\title{
The contribution analysis of knee compression bandage and arm swing control on maximum horizontal distance in standing long jump
}

\author{
Che-Cheong Ryew, Seung-Hyun Hyun* \\ Department of Kinesiology, College of Natural Science, Jeju National University, Jeju, Korea
}

The aim of the study was to analyze the effect of knee compression bandage and arm swing control on the maximum horizontal distance and ground reaction force variables in standing long jump. Adult male ( $n=8$; mean age, $22.75 \pm 1.98$ years; mean heights, $1.77 \pm 0.03 \mathrm{~m}$; mean weights, $71.82 \pm 12.87 \mathrm{~kg}$ ) participated in the experiment. The results obtained from variables of ground reaction force (GRF) in medial lateral, anterior posterior (AP), vertical (V) direction, resultant GRF (RGRF), decay rate (\%), and maximum horizontal distance (MHD) were as follows; MHD, AP GRF, VGRF, RGRF (AP-V), and ratio of load reduction (\%) showed more effective result under both wearing of knee compression bandage and arm swing. In analysis of main effects, MHD, AP GRF, VGRF, and RGRF showed more increased value in case of wearing of knee com- pression bandage than as was not. While arm swing during standing long jump (SLJ) works as important factor to MHD, showed more effective factor in exercise rehabilitation, injury prevention and swell treatment etc. in wearing of worn knee compression bandage. Therefore it was assumed that arm swing and wearing of knee compression bandage may improve the performance of SLJ. Also, the characteristics of knee compression bandage suggest that it can be a great help for those participating in exercise rehabilitation.

Keywords: Standing long jump, Knee compression band, Arm swing, Horizontal distance, Resultant ground reaction force, Decay rate

\section{INTRODUCTION}

Clothes on the basis of body pressure for the purpose of optimized circulation of blood on body mainly were utilized in an area of medical therapy (Duffield and Portus, 2007; MacRae et al., 2011; Onorati et al., 2003; Schraibman et al., 1982). The kinds of which was consisted of largely the stocking, sleeve, garment of upper and lower body, degree of pressuring on body was depended upon fabric characteristics of textiles (MacRae et al., 2011).

Compression applied to sports athlete increased body temperature during warm-up protocol and performance of repetitive jumping (Doan et al., 2003; Kraemer et al., 1996), also improved positive psychological stability, sensory improvement of improvement of proprioception of hip joint, and strengthen subsidiary function of muscular coordination by vibration reduction at land- ing (Bringard et al., 2006; Kemmler et al., 2009).

Of various kinds of exercise, standing long jump (SLJ) is basic movement of human which requires complex coordination of lower and upper extremities, and requires efficient control between whole body and all body segments (Ashby and Delp, 2006; Ashby and Heegaard, 2002). Particularly due to characteristics of SLJ which needs explosive power of lower limb, also it used to monitor the response time of sport training program and physical fitness in firing officer and military troop etc. (Wakai and Linthorne, 2005). Because SLJ is closly related with isokinetic power of lower limbs, and is good predictable instrument for performance of sprint and SLJ (Wiklander and Lysholm, 1987).

Also SLJ may provide effective information on improving the performance of horizontal distance due to good predictable instrument of exercise test and motor performance. That is, function of
${ }^{*}$ Corresponding author: Seung-Hyun Hyun (iD https://orcid.org/0000-0001-6348-6413 Department of Kinesiology, College of Natural Science, Jeju National University, 102 Jejudaehak-ro, Jeju 63243, Korea

Tel: +82-64-754-2273, Fax: +82-64-757-1752, E-mail: hshyun0306@jejunu.ac.kr Received: January 17, 2018 / Accepted: February 23, 2018
This is an Open Access article distributed under the terms of the Creative Commons Attribution Non-Commercial License (http://creativecommons.org/licenses/by-nc/4.0/) which permits unrestricted non-commercial use, distribution, and reproduction in any medium, provided the original work is properly cited. 
upper extremities may contribute to improvement of jumping height by increasing of center of gravity's velocity at take-off (Feltner et al., 1999; Harman et al., 1990; Luhtanen and Komi, 1978; Shetty and Etnyre, 1989), thus total vertical height of center of gravity (Lees and Barton, 1996) and increasing of maximum vertical ground reaction force (GRF) (Harman et al., 1990; Shetty and Etnyre, 1989).

In addition, the assertion of which movement of arm's rotation of during SLJ was helpful for the control of optimizing landing position (Herzog, 1986) was related with "theory of hold back" which should limit and restrain the activation of lower limb extensors against excessive forward rotation which hampers the proper landing in case of without arm's function during propulsive phase (Ashby and Delp, 2006; Ashby and Heegaard, 2002).

Like this, clothes on the basis of body pressure was helpful for not only improvement of motor performance, but also applied to injury prevention, exercise rehabilitation and injury treatment on the forfeiture of motor sensory with malfunction of posture control by compression on the body (Freeman et al., 1965), but was not improved on the distance of maximum throwing (Duffield and Portus, 2007), on the function repetitive sprinting (MacRae et al., 2011), and on the performance of long distance running and cycling time (Ali et al., 2007). But in worldwide, athletes who participates in more powerful sports gradually prefers to wears clothes on the basis of body pressure (Fu et al., 2012), and it is necessary to investigate concrete mechanism of effect of correlation and mechanism on motor performance whether wearing of knee compression bandage and the movement of arm swing or not SLJ.

Therefore the aim of the study investigates quantitatively the difference of jumping performance in each case of arm swing control and wearing of knee compression bandage during SLJ.

\section{MATERIALS AND METHODS}

\section{Subject}

The subject participated in the study consist of health adult male ( $\mathrm{n}=8$; mean age, $22.75 \pm 1.98$ years; mean heights, $1.77 \pm$ $0.03 \mathrm{~m}$; mean weights, $71.82 \pm 12.87 \mathrm{~kg}$ ). The subjects had no problems in performing maximum SLJ, and had no careers of exercise rehabilitation treatment and vertebrae or lower leg's injury within 1 year recently. The subjects who consented on the preliminary detail explanation on the management of individual information, experimental procedure and method etc. participated in the experiment.

\section{Experimental procedure}

All subjects performed warm-up exercise over 20 min based on fixed time before each trial's experiment. Both arm was restricted in a condition of crossed $\mathrm{X}$ type with bandage to control the movement of upper arm swing.

SLJ was performed at randomly knee compression bandage wearing on GRF (AMTI-OR-7, Advanced Mechanical Technology Inc., Watertown, MA, USA) and data was sampled at 1,000 $\mathrm{Hz}$. Mat for injury prevention was installed on bilateral surface of both path of GRF plate when considered falling or failure of stabilization of center of gravity, and successful 1 trial was selected as analysis sample on the basis of subjective judge, subject's statement, condition of data transfer etc. of total 5 times trials.

And then, knee compression bandage (Neoprene Knee Support, Hengshangtong International Trade Co., LTD, Qingdao, China) was attached on both knees according to suggested manual. Jumping distance for each trial was recorded by 2 point of deci$\mathrm{mal}$, and measured on maximum horizontal distance (MHD) from jump line to heel touch point.

\section{Definition of analysis phase}

Analysed variables consisted of GRF in medial lateral (ML), anterior posterior (AP), vertical $(\mathrm{V})$ direction, resultant GRF (RGRF) in AP-V direction, decay rate (\%), and MHD. GRF (N) was obtained from normalized value of body weight. Also decay rate (\%) was calculated from model of Munro et al. (1987).

$$
\text { Decay rate }=\left(\mathrm{F}_{0}-\mathrm{PVF}\right) /\left(\mathrm{T}_{0}-\mathrm{TPVF}\right)
$$

Peak vertical force (PVF) means maximum vertical ground reaction force value at jumping, $\mathrm{F}_{0}$ means $0 \mathrm{GRF}$ value after jumping, $\mathrm{T}_{0}$ means occurring point of $\mathrm{F}_{0}$, and time peak vertical force (TPVF) means occurring point of PVF respectively.

RGRF in a situation of jumping in horizontal direction is as follows;

\section{$\mathrm{RGRF}=\sqrt{\left(\mathrm{AP} \mathrm{GRF}^{2}+\mathrm{VGRF}^{2}\right)}$}

\section{Analysis and process of data}

The average and the standard deviation of the calculated variables were obtained using IBM SPSS Statistics ver. 21.0 (IBM Co., Armonk, NY, USA), and was performed repeated measures twoway analysis of variance and performed the post hoc test (Duncan) at $(P<0.05)$ in case of significant level respectively. 


\section{RESULTS}

Analyzed result of MHD according to utilization of upper arm condition and knee compression bandage during SLJ was as (Table 1), and swing arm showed the most improved MHD in condition of wearing of knee compression bandage. In analyzed main effects, swing arm showed longer MHD than control arm, the difference was significant. MHD change with wearing of knee compression bandage and interaction between upper arm condition and knee compression bandage did not show.

Analyzed result of GRF during SLJ was as (Table 2), while ML and GRF variables showed irregular pattern, but AP GRF, VGRF, RGRF, and decay rate in case of swing arm worn the knee compression bandage showed the most improved pattern. In analyzed main effects, ML GRF did not show difference with wearing of knee compression bandage.

AP GRF did not show difference but swing arm showed larger difference than control arm with wearing of knee compression bandage, VGRF did not showed difference with upper arm condition, but showed more increased in knee band than control band with wearing of knee compression bandage. RGRF of AP GRF and VGRF more increased in knee band than control band with wearing of knee compression bandage and all the above showed significant difference respectively but decay rate did not show difference and interaction with wearing of knee compression bandage and upper arm condition.

\section{DISCUSSION}

It was reported that clothes on the basis of body pressure was

Table 1. Long jumping performance according to the knee compression band and arm swing

\begin{tabular}{|c|c|c|c|c|c|c|c|}
\hline \multirow{2}{*}{ Section } & \multirow{2}{*}{ Upper arm condition } & \multicolumn{3}{|c|}{ Knee compression band } & \multirow{2}{*}{ Source } & \multirow{2}{*}{$F$} & \multirow{2}{*}{$P$-value } \\
\hline & & Control band & Knee band & Total average & & & \\
\hline \multirow{3}{*}{$\begin{array}{l}\text { Max. horizontal } \\
\text { distance }\end{array}$} & Control arm & $194.37 \pm 12.54$ & $190.12 \pm 6.93$ & $192.25 \pm 10.03$ & K & 0.129 & 0.722 \\
\hline & Swing arm & $223.37 \pm 9.78$ & $225.12 \pm 9.34$ & $224.25 \pm 9.28$ & U & 84.345 & $<0.001^{* * *}$ \\
\hline & Total average & $208.87 \pm 18.50$ & $207.62 \pm 19.74$ & $208.25 \pm 18.83$ & $\mathrm{~K} \times \mathrm{U}$ & 0.741 & 0.397 \\
\hline
\end{tabular}

Values are presented as mean \pm standard deviation $(\mathrm{cm})$.

$\mathrm{K}$, main effect of the knee compression band; $\mathrm{U}$, main effect of the upper arm; $\mathrm{K} \times \mathrm{U}$, interaction.

${ }^{* * *} P<0.001$.

Table 2. Ground reaction force variables according to the knee compression band and arm swing

\begin{tabular}{|c|c|c|c|c|c|c|c|}
\hline \multirow{2}{*}{ Section } & \multirow{2}{*}{ Upper arm condition } & \multicolumn{3}{|c|}{ Knee compression band } & \multirow{2}{*}{ Source } & \multirow{2}{*}{$F$} & \multirow{2}{*}{$P$-value } \\
\hline & & Control band & Knee band & Total average & & & \\
\hline \multirow[t]{3}{*}{ Medial-lateral GRF (N/BW) } & Control arm & $0.05 \pm 0.04$ & $0.05 \pm 0.04$ & $0.05 \pm 0.04$ & K & 1.142 & 0.294 \\
\hline & Swing arm & $0.08 \pm 0.06$ & $0.04 \pm 0.06$ & $0.06 \pm 0.06$ & U & 0.247 & 0.623 \\
\hline & Total average & $0.07 \pm 0.05$ & $0.05 \pm 0.05$ & $0.06 \pm 0.05$ & $\mathrm{~K} \times \mathrm{U}$ & 0.506 & 0.483 \\
\hline \multirow[t]{3}{*}{ Anterior-posterior GRF (N/BW) } & Control arm & $0.72 \pm 0.05$ & $0.70 \pm 0.07$ & $0.71 \pm 0.06$ & K & 0.516 & 0.478 \\
\hline & Swing arm & $0.74 \pm 0.09$ & $0.80 \pm 0.11$ & $0.77 \pm 0.10$ & U & 4.427 & $0.044^{*}$ \\
\hline & Total average & $0.73 \pm 0.07$ & $0.75 \pm 0.10$ & $0.74 \pm 0.09$ & $\mathrm{~K} \times \mathrm{U}$ & 1.721 & 0.200 \\
\hline \multirow[t]{3}{*}{ Vertical GRF (N/BW) } & Control arm & $1.96 \pm 0.25$ & $2.08 \pm 0.14$ & $2.02 \pm 0.21$ & K & 5.004 & $0.033^{*}$ \\
\hline & Swing arm & $2.01 \pm 0.21$ & $2.22 \pm 0.21$ & $2.11 \pm 0.23$ & $U$ & 1.173 & 0.201 \\
\hline & Total average & $1.98 \pm 0.23$ & $2.15 \pm 0.19$ & $2.07 \pm 0.22$ & $\mathrm{~K} \times \mathrm{U}$ & 0.260 & 0.614 \\
\hline \multirow[t]{3}{*}{ Resultant AP-V GRF (N/BW) } & Control arm & $2.08 \pm 0.24$ & $2.19 \pm 0.14$ & $2.14 \pm 0.20$ & K & 4.706 & $0.039^{*}$ \\
\hline & Swing arm & $2.14 \pm 0.21$ & $2.35 \pm 0.22$ & $2.25 \pm 0.23$ & U & 2.223 & 0.147 \\
\hline & Total average & $2.11 \pm 0.22$ & $2.27 \pm 0.19$ & $2.19 \pm 0.22$ & $\mathrm{~K} \times \mathrm{U}$ & 0.425 & 0.520 \\
\hline \multirow[t]{3}{*}{ Decay rate (N/BW/sec) } & Control arm & $-17.31 \pm 5.98$ & $-19.96 \pm 6.56$ & $-18.63 \pm 6.21$ & K & 0.548 & 0.465 \\
\hline & Swing arm & $-19.23 \pm 7.67$ & $-20.04 \pm 6.17$ & $-19.63 \pm 6.74$ & U & 0.183 & 0.672 \\
\hline & Total average & $-18.27 \pm 6.72$ & $-20.00 \pm 6.15$ & $-19.13 \pm 6.40$ & $\mathrm{~K} \times \mathrm{U}$ & 0.153 & 0.699 \\
\hline
\end{tabular}

Values are presented as mean \pm standard deviation.

BW, body weight; GRF, ground reaction force; AP-V, anterior-posterior and vertical; $K$, main effect of the knee compression band; $U$, main effect of the upper arm; $K \times U$, interaction.

${ }^{*} P<0.05$. 
effective in exercise rehabilitation and treatment area, but showed opposite result except for a few efficacies in sports (Michael et al., 2014). SLJ achieved by intersegmental coordination of body acts as important factor in measurement of muscular power, but rarely not known on the mechanism of motor function according to the utilization of upper arm condition and knee compression bandage.

The result of the study did not show effectiveness of knee compression bandage, but rather swing arm than control arm showed positive effectiveness on the change of MHD during SLJ. Ashby and Heegaard (2002) reported that height of center of gravity was jumped over $36 \mathrm{~cm}$ in case of swing arm, which improved velocity of center of gravity was coincided with improved portion of 24 $\mathrm{cm}$. Particularly, it was assumed that this result was contributed to mechanism to improve jumping performance and additional downward force on body at the proper point which could exert the VGRF by hip and knee extensor in case of swing arm during SLJ (Feltner et al., 1999; Harman et al., 1990).

That is, it was verified that swing arm of this study could cause maximum power in specific point of time during SLJ, and 0.71 times of body weight in case of control arm, but rather higher 0.77 times in case of swing arm in analysed main effects of AP GRF. Ashby and Heegaard (2002) reported that it showed 2.31 times of body weight in case of swing arm, but rather higher 2.25 times in case of control arm, which was similar results with this study. While knee compression bandage influenced greatly on vertical GRF in this study, which was similar result with knee compression bandage (Doan et al., 2003; Kraemer et al., 1996), and furthermore more influential on increase of resultant GRF.

Munro et al. (1987) defined decay rate as coming nearly " 0 -value" of force at take off of foot from ground during running. Decay rate of this study was contributed to GRF magnitude and take-off time at a point of take off during SLJ, which showed lowest value in case of control band and control arm.

Whether this result due to "theory of hold back" which should limit and restrain the activation of lower limb extensors against excessive forward rotation which hampers the proper landing in case of without arm's function during propulsive phase (Ashby and Delp, 2006; Ashby and Heegaard, 2002) or not, it is necessary to clarify firstly relation between AP and VGRF and rotational force of whole body in advance to verify the relation between decay rate and MHD.

When considering the above, wearing of knee compression bandage contribute to increase of the VGRF and RGRF, particularly when work together with swing arm on the GRF components and showed MHD. That is, it was suggested that wearing of knee compression bandage have not only an effects on therapy of forfeiture of motor sensory, exercise rehabilitation, injury prevention, and swell (Freeman et al., 1965; Lawrence and Kakkar, 1980; Onorati et al., 2003; Schraibman et al., 1982), but also on improvement of MHD during SLJ. Also, the characteristics of knee compression bandage suggest that it can be a great help for those participating in exercise rehabilitation.

Swing arm during movement of horizontal direction may reduce unstable AP GRF and magnitude of impulse force at touchdown (Shetty and Etnyre, 1989). That is, it was suggested that wearing of knee compression bandage have not only an effects on exercise rehabilitation, injury prevention, and but also on improvement of MHD during SLJ. Therefore it is necessary to verify closely an effect of mechanism and relation among variables due to wearing of knee compression bandage in further studies.

\section{CONFLICT OF INTEREST}

No potential conflict of interest relevant to this article was reported.

\section{ACKNOWLEDGMENTS}

This research was supported by the 2018 scientific promotion program funded by Jeju National University.

\section{REFERENCES}

Ali A, Caine MP, Snow BG. Graduated compression stockings: physiological and perceptual responses during and after exercise. J Sports Sci 2007;25:413-419.

Ashby BM, Delp SL. Optimal control simulations reveal mechanisms by which arm movement improves standing long jump performance. J Biomech 2006;39:1726-1734.

Ashby BM, Heegaard JH. Role of arm motion in the standing long jump. J Biomech 2002;35:1631-1637.

Bringard A, Perrey S, Belluye N. Aerobic energy cost and sensation responses during submaximal running exercise: positive effects of wearing compression tights. Int J Sports Med 2006;27:373-378.

Doan BK, Kwon YH, Newton RU, Shim J, Popper EM, Rogers RA, Bolt LR, Robertson M, Kraemer WJ. Evaluation of a lower-body compression garment. J Sports Sci 2003;21:601-610.

Duffield R, Portus M. Comparison of three types of full-body compression garments on throwing and repeat-sprint performance in cricket players. Br J Sports Med 2007;41:409-414. 
Feltner ME, Fraschetti DJ, Crisp RJ. Upper extremity augmentation of lower extremity kinetics during countermovement vertical jumps. J Sports Sci 1999;17:449-466.

Freeman MA, Dean MR, Hanham IW. The etiology and prevention of functional instability of the foot. J Bone Joint Surg Br 1965;47:678-685.

Fu W, Liu Y, Zhang S, Xiong X, Wei S. Effects of local elastic compression on muscle strength, electromyographic, and mechanomyographic responses in the lower extremity. J Electromyogr Kinesiol 2012;22:44-50.

Harman EA, Rosenstein MT, Frykman PN, Rosenstein RM. The effects of arms and countermovement on vertical jumping. Med Sci Sports Exerc 1990;22:825-833.

Herzog W. Maintenance of body orientation in the flight phase of long jumping. Med Sci Sports Exerc 1986;18:231-241.

Kemmler W, von Stengel S, Köckritz C, Mayhew J, Wassermann A, Zapf J. Effect of compression stockings on running performance in men runners. J Strength Cond Res 2009;23:101-105.

Kraemer WJ, Bush JA, Bauer JA, Triplett-McBride NT, Paxton NJ, Clemson A, Koziris LP, Mangino LC, Fry AC, Newton RU. Influence of compression garments on vertical jump performance in NCAA division I volleyball players. J Strength Cond Res 1996;10:180-183.

Lawrence D, Kakkar VV. Graduated, static, external compression of the lower limb: a physiological assessment. Br J Surg 1980;67:119-121.

Lees A, Barton G. The interpretation of relative momentum data to assess the contribution of the free limbs to the generation of vertical velocity in sports activities. J Sports Sci 1996;14:503-511.

Luhtanen P, Komi RV. Segmental contribution to forces in vertical jump. Eur J Appl Physiol Occup Physiol 1978;38:181-188.

MacRae BA, Cotter JD, Laing RM. Compression garments and exercise: garment considerations, physiology and performance. Sports Med 2011;41:815-843.

Michael JS, Dogramaci SN, Steel KA, Graham KS. What is the effect of compression garments on a balance task in female athletes? Gait Posture 2014;39:804-809.

Munro CF, Miller DI, Fuglevand AJ. Ground reaction forces in running: a reexamination. J Biomech 1987;20:147-155.

Onorati D, Rossi GG, Idiazabal G. Effect of elastic stockings on edema related to chronic venous insufficiency. Videocapillaroscopic assessment. J Mal Vasc 2003;28:21-23.

Schraibman IG, Lewis B, Parmar JR. Clinical comparison of elastic supports for venous diseases of the lower limb and thrombosis prevention. Phlebologie 1982;35:61-71.

Shetty AB, Etnyre BR. Contribution of arm movement to the force components of a maximum vertical jump. J Orthop Sports Phys Ther 1989; 11:198-201.

Wakai M, Linthorne NP. Optimum take-off angle in the standing long jump. Hum Mov Sci 2005;24:81-96.

Wiklander J, Lysholm J. Simple tests for surveying muscle strength and muscle stiffness in sportsmen. Int J Sports Med 1987;8:50-54. 